\title{
Influence of malnutrition stage according to GLIM 2019 criteria and SGA method on the quality of life of patients with advanced cancer - a prospective study
}

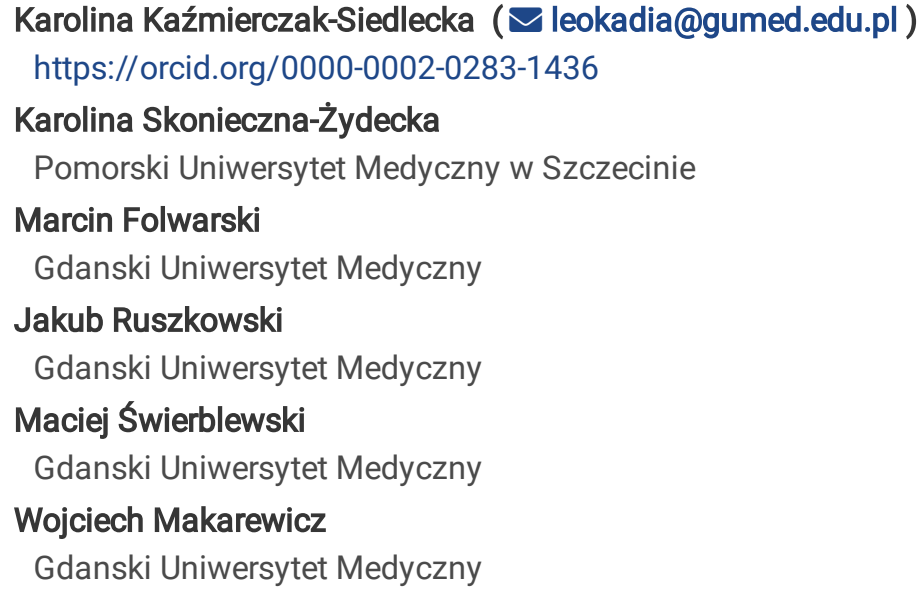

Research note

Keywords: malnutrition, advanced cancer, quality of life, GLIM criteria, SGA tool

Posted Date: May 22nd, 2020

DOI: https://doi.org/10.21203/rs.3.rs-28027/v1

License: (c) (i) This work is licensed under a Creative Commons Attribution 4.0 International License. Read Full License 


\section{Abstract}

Objectives

The primary aims of this study were the assessment of nutritional status based on Global Leadership Initiative on Malnutrition (GLIM) criteria 2019 and Subjective Global Assessment (SGA) as well as quality of life (QOL) with World Health Organization Quality of LifeBREF questionnaire (WHOQOL-BREF) of advanced cancer patients. The secondary aim was to investigate the impact of severity of malnutrition on QOL of these patients.

Results

This study included 33 advanced cancer patients from Nutritional Counselling Centre Copernicus in Gdansk and Department of Surgical Oncology, Medical University in Gdansk, Poland. The majority of patients suffered from head/neck ( $n=12,33.33 \%)$ and espohageal cancer $(n=11,33.33 \%)$. According to the SGA method, most of the patients were malnourished ( $n=14,42.42 \%)$ and severely malnourished ( $n=14,42.42 \%)$. Based on the GLIM criteria, $69.7 \%$ of patients $(n=23)$ were severely malnourished. Among all participants, the highest impairment of QOL in self-assessment of satisfaction of health, environmental, and psychological domain was observed. The severe malnutrition significantly impairs QOL in psychological (GLIM stage 2, p=0.0033; SGA C, p=0.0310) and somatic domain (GLIM stage 2, p=0.0423). This is the first study assessing the impact of severity of malnutrition based on new GLIM criteria on QOL of advanced cancer patients.

\section{Introduction}

The complexity of anti-cancer therapy including multidisciplinary support is extremely important for advanced cancer patients. According to the European Society for Clinical Nutrition and Metabolism (ESPEN) guidelines, the nutritional status of all cancer patients should be screened regularly due to high risk of malnutrition [1]. Additionally, the risk is higher in patients with advanced stage of malignancy. The presence of malnutrition limits the response to the anti-cancer therapy [1]. Therefore, the assessment of nutritional status of these patients is strongly required [2,3]. Currently, several screening tools are available to assess the nutritional status, for instance Nutritional Risk Screening 2002 (NRS 2002) or Subjective Global Assessment (SGA). In Kaźmierczak-Siedlecka et al. study including 84 patients with gastric and esophageal cancer, it was shown that all patients qualified for home enteral nutrition were at risk of malnutrition or malnourished, thus, they required nutritional treatment. Of high importance $40.4 \%$ of were scored " 5 ” in NRS 2002 tool [4]. Thoresen et al. have reported that 65.22\% advanced cancer patients were malnourished according to the SGA method [5]. SGA has been shown to be the best predictor of clinical outcome in comparison with NRS 2002 [6, 7]. Notably, SGA is easy-to-use and noninvasive. The modified version of SGA is Patients-Generated Subjective Global Assessment (PG-SGA), which additionally reports on the presence of nutritional symptoms and short-term weight loss [8]. Global Leadership Initiative on Malnutrition (GLIM) proposed a grading of the severity of malnutrition; stage 1 (moderate) and stage 2 (severe) [9]. It should be emphasized, that GLIM criteria were published in 2019 , therefore, the data regarding these criteria and advanced cancer patients is limited [9].

The presence of cancer significantly deteriorates QOL $[10,11]$. In Ahlam et al. study, it was shown that, the majority of Moroccan patients with advanced palliative care experienced deteriorated QOL in all aspects of physical and emotional functioning [12]. Smith et al. have reported that pain, anxiety, and depression were associated with the impairment of QOL of advanced cancer patients [13]. Overall, the care of advanced cancer patients involves the assessment and consequently maintenance or improvement of QOL [10].

The primary aims of this study were to assess nutritional status and the QOL in cancer patients at advanced stage of the malignancy. The secondary aim was to investigate the impact of severity of malnutrition on QOL of these patients.

\section{Methods}

\section{Patients}

Participants ( $\mathrm{n}=35$ ) were recruited by a surgeon and nutritionist in Nutritional Counselling Copernicus Centre in Gdansk and Department of Surgical Oncology (Medical University of Gdansk, Poland). Inclusion criteria were: $\geq 18$ years old (y.o.), the presence of advanced stage cancer of upper gastrointestinal tract or head and neck cancer, written, informed consent to take part in this study.

Study design

Page 2/9 
The flow-chart of this study is presented in Fig. 1. A total of 35 patients were assessed as eligible for this study. Among these, 2 were excluded, because they did not give a written consent to participate in this study.

\section{Outcomes}

The assessment of nutritional status in study participants was done using SGA method, which is divided into 3 parts: medical interview, physical examination, and the final assessment of nutritional status. Malnutrition was also categorized into stage 1 and stage 2 using GLIM criteria.

GLIM stage 1 requires one of the following criteria to be met:

1. unintentional weight loss (5-10\% within the past 6 months, or $10-20 \%$ beyond 6 months),

2. low BMI ( $<20 \mathrm{~kg} / \mathrm{m}^{2}$ if $<70 \mathrm{yr} .,<22 \mathrm{~kg} / \mathrm{m}^{2}$ if $\geq 70 \mathrm{yr}$.),

3. reduced muscle mass (mild to moderate deficit).

GLIM stage 2 requires one of the following criteria to be met:

1. unintentional weight loss ( $>10 \%$ within the past 6 months or $>20 \%$ beyond 6 months),

2. low BMI ( $<18.5 \mathrm{~kg} / \mathrm{m}^{2}$ if $<70 \mathrm{yr} .,<20 \mathrm{~kg} / \mathrm{m}^{2}$ if $\geq 70 \mathrm{yr}$.),

3. reduced muscle mass (severe deficit).

Another outcome was to assess QOL in advanced cancer patients. This was done using the World Health Organization Quality of LifeBREF (WHOQOL-BREF) questionnaire which consists of 26 questions divided into 4 domains (D1 - environmental, D2 - psychological, D3 - somatic, and D4 - social factors). Additionally, first question (Q1) "How would you rate your quality of life?" is patients' selfassessment of QOL (1 point mean "very poor" and 5 "very good") and second (Q2) "How satisfied are you with your health?" regards patients' self-assessment of health status ( 1 point means "very dissatisfied" and 5 "very satisfied").

\section{Statistical analysis}

The statistical analyses have been performed using the STATISTICA version 13.0 and Microsoft Excel 2019 PL. Normality was tested with Shapiro-Wilk test. In case of nutritional status assessment, the significance of difference between groups was tested with Pearson's chi-squared test. To compare the QOL scores between groups, the Mann-Whitney $\mathrm{U}$ and the Kruskal-Wallis $\mathrm{H}$ tests were used, as appropriate. The statistical significance level of $p=0.05$ was adopted.

\section{Results}

\section{Patients' characteristics}

A total of 35 participants were invited to the study. 2 patients disagreed to take part in the study and were excluded. The statistical analyses were performed for observed cases only. The majority of patients suffered from head/neck $(n=12,33.33 \%)$ and espohageal cancer $(n=11,33.33 \%)$. 
Table 1

Patients' characteristics.

\begin{tabular}{|c|c|}
\hline & All participants $(n=33)$ \\
\hline Age (yr.) & $58.91 \pm 10.57$ \\
\hline Gender F/M n (\%) & $8 / 25(24.24 / 75.76)$ \\
\hline Diagnosis n (\%) & $11(33.33)$ \\
\hline Esophageal cancer & $10(30.30)$ \\
\hline Gastric cancer & $12(33.33)$ \\
\hline Head/neck cancer & $5(15.15)$ \\
\hline$\neg$ Pharyngeal cancer & $1(3.03)$ \\
\hline$\neg$ Gum cancer & $2(6.06)$ \\
\hline$\neg$ Tonsil cancer & $1(3.03)$ \\
\hline$\neg$ Craniofacial cancer & $1(3.03)$ \\
\hline$\neg$ Sinus cancer & $2(6.06)$ \\
\hline \multicolumn{2}{|l|}{$\neg$ Tongue cancer } \\
\hline $\mathrm{n}(\%)$ & $1(3.03)$ \\
\hline ONS & $4(12.12)$ \\
\hline Naso-gastric tube & $14(42.42)$ \\
\hline PEG & 13 (39.39) \\
\hline Jejunostomy & $1(3.03)$ \\
\hline \multicolumn{2}{|l|}{ NCJ } \\
\hline $\mathrm{BMI}\left(\mathrm{kg} / \mathrm{m}^{2}\right)$ & $21.78 \pm 4.24$ \\
\hline
\end{tabular}

\section{Nutritional status}

As to SGA evaluation, most of the patients were malnourished $(n=14,42.42 \%)$ and severely malnourished $(n=14,42.42 \%)$. Patients with head/neck cancer were more often severely malnourished in comparison to those with esophageal and gastric cancer $(n=7$, $58.33 \%$ vs. $n=4,36.36 \%$ and $n=3,30 \%$, respectively); however, the difference was not statistically significant $(p=0.70675)$.

According to the 2019 GLIM criteria, $n=23$ (69.7\% of patients) were severely malnourished. Patients with head/neck advanced cancer suffered from severe malnutrition more often compared to those with esophageal and gastric advanced cancer $(n=9,69.7 \% v s$. $n=8$, $72.73 \%$ and $n=6,60 \%$, respectively); however, the difference was not statistically significant $(p=0.72151)$.

\section{Quality of life}

The assessment of QOL is presented in Table 2. Moderate malnourished patients (GLIM stage 1) had better QOL in Q1, Q2, and all domains compared to severe malnourished individuals; however, the difference was statistically significant in Q1, D1, and D2. Patients at risk of malnutrition (SGA A) had better QOL in Q1 and all domains compared to malnourished subjects (SGA C); the difference was significant statistically in D2 ( $p=0.0310)$. Additionally, moderate malnourished (GLIM stage 1) patients with advanced head/neck cancer had better QOL in Q2 and all domains compared to those severely malnourished (GLIM stage 2); the difference was not significant statistically.

If take into consideration patients' self-assessment of QOL, a total of $36.36 \%(n=12)$ assessed self QOL as "poor" and $54.55 \%(n=18)$ of them declared dissatisfaction of self health. 
Table 2

The assessment of QOL.

\begin{tabular}{|c|c|c|c|c|c|c|c|c|c|c|c|c|}
\hline & Q1 & $p$ & Q2 & $p$ & D1 & $p$ & D2 & $p$ & D3 & $p$ & D4 & $p$ \\
\hline $\begin{array}{l}\text { All } \\
\text { participants }\end{array}$ & $\begin{array}{l}2.88 \\
\pm \\
0.89\end{array}$ & - & $\begin{array}{l}2.36 \\
\pm 0.9\end{array}$ & - & $\begin{array}{l}12.15 \\
\pm 1.68\end{array}$ & - & $\begin{array}{l}13.06 \\
\pm 2.14\end{array}$ & - & $\begin{array}{l}15.3 \\
\pm 2.59\end{array}$ & - & $\begin{array}{l}14.79 \\
\pm 2.06\end{array}$ & - \\
\hline $\begin{array}{l}\text { Head/neck } \\
\text { cancer }\end{array}$ & $\begin{array}{l}3.08 \\
\pm 0.9\end{array}$ & \multirow[t]{3}{*}{0.4603} & $\begin{array}{l}2.33 \\
\pm \\
0.78\end{array}$ & \multirow[t]{3}{*}{0.9979} & $\begin{array}{l}12 \pm \\
1.91\end{array}$ & 0.9655 & $\begin{array}{l}12.17 \\
\pm 2.41\end{array}$ & \multirow[t]{3}{*}{0.1841} & $\begin{array}{l}14.25 \\
\pm 2.42\end{array}$ & \multirow[t]{3}{*}{0.1331} & $\begin{array}{l}14.17 \\
\pm 1.85\end{array}$ & \multirow[t]{3}{*}{0.3834} \\
\hline $\begin{array}{l}\text { Esophageal } \\
\text { cancer }\end{array}$ & $\begin{array}{l}2.64 \\
\pm \\
0.81\end{array}$ & & $\begin{array}{l}2.36 \\
\pm \\
1.03\end{array}$ & & $\begin{array}{l}12.18 \\
\pm 1.47\end{array}$ & & $\begin{array}{l}13.27 \\
\pm 1.85\end{array}$ & & $\begin{array}{l}15.64 \\
\pm 2.91\end{array}$ & & $\begin{array}{l}15.27 \\
\pm 2.33\end{array}$ & \\
\hline $\begin{array}{l}\text { Gastric } \\
\text { cancer }\end{array}$ & $\begin{array}{l}2.9 \\
\pm \\
0.99\end{array}$ & & $\begin{array}{l}2.4 \\
\pm \\
0.97\end{array}$ & & $\begin{array}{l}12.3 \\
\pm 1.77\end{array}$ & & $\begin{array}{l}13.9 \\
\pm 1.85\end{array}$ & & $\begin{array}{l}16.2 \\
\pm 2.2\end{array}$ & & $15 \pm 2$ & \\
\hline $\begin{array}{l}\text { All } \\
\text { participants }\end{array}$ & $\begin{array}{l}3.4 \\
\pm \\
084\end{array}$ & \multirow[t]{2}{*}{0.0382} & $\begin{array}{l}2.4 \\
\pm \\
1\end{array}$ & \multirow[t]{2}{*}{0.9539} & $\begin{array}{l}13.5 \\
\pm 0.97\end{array}$ & 0.0033 & $\begin{array}{l}13.8 \\
\pm 2.7\end{array}$ & \multirow[t]{2}{*}{0.0423} & $\begin{array}{l}16.4 \\
\pm 2.63\end{array}$ & \multirow[t]{2}{*}{0.1439} & $\begin{array}{l}15.9 \\
\pm 1.91\end{array}$ & \multirow[t]{2}{*}{0.0565} \\
\hline $\begin{array}{l}\text { GLIM Stage } \\
1 \\
\text { GLIM Stage } \\
2\end{array}$ & $\begin{array}{l}2.65 \\
\pm \\
0.83\end{array}$ & & $\begin{array}{l}2.35 \\
\pm \\
0.83\end{array}$ & & $\begin{array}{l}11.57 \\
\pm 1.59\end{array}$ & & $\begin{array}{l}12.74 \\
\pm 1.81\end{array}$ & & $\begin{array}{l}14.83 \\
\pm 2.48\end{array}$ & & $\begin{array}{l}14.3 \\
\pm 1.96\end{array}$ & \\
\hline $\begin{array}{l}\text { Head/neck } \\
\text { cancer }\end{array}$ & $\begin{array}{l}2.67 \\
\pm \\
1\end{array}$ & \multirow[t]{2}{*}{0.4818} & $\begin{array}{l}2.67 \\
\pm \\
1\end{array}$ & \multirow[t]{2}{*}{0.7273} & $\begin{array}{l}13.67 \\
\pm 1.15\end{array}$ & 0.1455 & $\begin{array}{l}12.67 \\
\pm 4.93\end{array}$ & \multirow[t]{2}{*}{0.4818} & $\begin{array}{l}14.33 \\
\pm 1.15\end{array}$ & \multirow[t]{2}{*}{0.8636} & $\begin{array}{l}15.33 \\
\pm 2.08\end{array}$ & \multirow[t]{2}{*}{0.2818} \\
\hline $\begin{array}{l}\text { GLIM Stage } \\
1 \\
\text { GLIM Stage } \\
2\end{array}$ & $\begin{array}{l}3.22 \\
\pm \\
0.83\end{array}$ & & $\begin{array}{l}2.22 \\
\pm \\
0.67\end{array}$ & & $\begin{array}{l}11.44 \\
\pm 1.81\end{array}$ & & $\begin{array}{l}12 \pm \\
1.32\end{array}$ & & $\begin{array}{l}14.22 \\
\pm 2.77\end{array}$ & & $\begin{array}{l}13.78 \\
\pm 1.72\end{array}$ & \\
\hline $\begin{array}{l}\text { Esophageal } \\
\text { cancer } \\
\text { GLIM Stage } \\
1 \\
\text { GLIM Stage } \\
2\end{array}$ & $\begin{array}{l}3.67 \\
\pm \\
0.58 \\
2.25 \\
\pm \\
0.46\end{array}$ & 0.0242 & $\begin{array}{l}2.67 \\
\pm \\
1.53 \\
2.25 \\
\pm \\
0.89\end{array}$ & 0.6303 & $\begin{array}{l}13.67 \\
\pm 0.58 \\
11.63 \\
\pm 1.3\end{array}$ & 0.0242 & $\begin{array}{l}15 \pm \\
1.73 \\
12.63 \\
\pm 1.51\end{array}$ & 0.0848 & $\begin{array}{l}18 \pm \\
2.65 \\
14.75 \\
\pm 2.6\end{array}$ & 0.1939 & $\begin{array}{l}17 \pm 1 \\
14.63 \\
\pm 2.39\end{array}$ & 0.1333 \\
\hline $\begin{array}{l}\text { Gastric } \\
\text { cancer }\end{array}$ & $\begin{array}{l}3.75 \\
\pm 0.5\end{array}$ & \multirow[t]{2}{*}{0.01905} & $\begin{array}{l}2 \pm \\
0.82\end{array}$ & \multirow[t]{2}{*}{0.4762} & $\begin{array}{l}13.25 \\
\pm 1.26\end{array}$ & 0.3524 & $\begin{array}{l}13.75 \\
\pm 0.96\end{array}$ & \multirow[t]{2}{*}{1.0000} & $\begin{array}{l}16.75 \\
\pm 2.87\end{array}$ & \multirow[t]{2}{*}{0.4762} & $\begin{array}{l}15.5 \\
\pm 2.38\end{array}$ & \multirow[t]{2}{*}{0.9143} \\
\hline $\begin{array}{l}\text { GLIM Stage } \\
1 \\
\text { GLIM Stage } \\
2\end{array}$ & $\begin{array}{l}2.33 \\
\pm \\
0.82\end{array}$ & & $\begin{array}{l}2.67 \\
\pm \\
1.03\end{array}$ & & $\begin{array}{l}11.67 \\
\pm 1.86\end{array}$ & & $\begin{array}{l}14 \pm \\
2.37\end{array}$ & & $\begin{array}{l}15.83 \\
\pm 1.83\end{array}$ & & $\begin{array}{l}14.67 \\
\pm 1.86\end{array}$ & \\
\hline $\operatorname{SGA}(A)$ & $\begin{array}{l}3.4 \\
\pm \\
0.89\end{array}$ & \multirow[t]{3}{*}{0.2399} & $\begin{array}{l}1.8 \\
\pm \\
0.84\end{array}$ & 0.1282 & $\begin{array}{l}13 \pm \\
0.71\end{array}$ & 0.1282 & $\begin{array}{l}14.4 \\
\pm 1.67\end{array}$ & \multirow{3}{*}{$\begin{array}{l}0.0019 \\
\text { (B vs C: } \\
0,0051 ; \\
\text { A vs C: } \\
0.0310 \text { ) }\end{array}$} & $\begin{array}{l}17.4 \\
\pm 3.21\end{array}$ & 0.2358 & $\begin{array}{l}15.6 \\
\pm 1.67\end{array}$ & \multirow[t]{3}{*}{0.3678} \\
\hline SGA (B) & $\begin{array}{l}2.93 \\
\pm 1\end{array}$ & & $\begin{array}{l}2.71 \\
\pm \\
0.91\end{array}$ & & $\begin{array}{l}12.21 \\
\pm 1.76\end{array}$ & & $\begin{array}{l}13.79 \\
\pm 2.52\end{array}$ & & $\begin{array}{l}15.14 \\
\pm 2.25\end{array}$ & & $\begin{array}{l}15.07 \\
\pm 2.06\end{array}$ & \\
\hline SGA (C) & $\begin{array}{l}2.64 \\
\pm \\
0.74\end{array}$ & & $\begin{array}{l}2.21 \\
\pm 0.8\end{array}$ & & $\begin{array}{l}11.79 \\
\pm 1.81\end{array}$ & & $\begin{array}{l}11.86 \\
\pm 1.1\end{array}$ & & $\begin{array}{l}14.71 \\
\pm 2.49\end{array}$ & & $\begin{array}{l}14.21 \\
\pm 2.15\end{array}$ & \\
\hline $\begin{array}{l}\text { SGA }(B+C) \\
\text { (vs. A) }\end{array}$ & $\begin{array}{l}2.79 \\
\pm \\
0.88\end{array}$ & 0,1895 & $\begin{array}{l}2.46 \\
\pm \\
0.88\end{array}$ & 0,1728 & $\begin{array}{l}12 \pm \\
1.76\end{array}$ & 0.2901 & $\begin{array}{l}12.82 \\
\pm 2.14\end{array}$ & 0.1286 & $\begin{array}{l}14.93 \\
\pm 2.34\end{array}$ & 0.1423 & $\begin{array}{l}14.64 \\
\pm 2.11\end{array}$ & 0.3641 \\
\hline
\end{tabular}


ONS - oral nutritional supplement; GLIM - Global Leadership Initiative on Malnutrition; SGA - Subjective Global Assessment; Q1 question 1 "How would you rate your quality of life?"; Q2 - question 2 "How satisfied are you with your health?"; D1 - environmental domain; D2 - psychological domain; D3 - somatic domain; D4 - social factors.

\section{Discussion}

The assessment and improvement of the nutritional status and QOL of cancer patients have been recognized as an important part of complex anti-cancer care. The previous trials have demonstrated that in cancer patients deterioration of QOL and nutritional status is frequent $[9,14,15]$. However, the studies assessing the severity of malnutrition in advanced cancer patients according to the GLIM criteria are strongly limited. Additionally, to the best of our knowledge, the present study is the first which assesses the impact of severity of malnutrition based on GLIM 2019 criteria on QOL in advanced cancer patients. The present study assessed the nutritional status and QOL in patients with head/neck, esophageal, and gastric advanced cancer.

In the present study, according to the SGA, $84.84 \%$ of patients were evaluated as malnourished (SGA B + C), while $42.42 \%$ subjects of all participants were severe malnourished (SGA C). Similarly, Wiegert et al. evaluated the nutritional status of advanced cancer patients in palliative care $(n=120)$ in Brazil using PG-SGA [16]. It was shown that, 94.2\% patients were malnourished [16]. Moreover, another trial including 172 advanced cancer patients also in Brazil, showed that $83.6 \%$ of these patients were malnourished (PG-SGA B + C) [17]. Patients with head/neck cancer are particularly at high risk of malnutrition. The location and size of tumour have a huge impact on swallowing process, thus food intake [18]. The present study has shown that patients with head/neck advanced cancer suffer from severe malnutrition (SGA C) more often compared to those with esophageal and advanced gastric cancer (58.33\% vs. $36.36 \%$ and $30 \%$, respectively; $p=0.70675)$. Similar results were noted if GLIM criteria were taken into consideration $(75 \%$ vs. $72.73 \%$ and $60 \%$ respectively; $p=0.72151)$.

Enteral nutrition is known as life-saving procedure; however, feeding via artificial access to the alimentary tract is not physiological and comfortable for patients [19]. Patients with head/neck advanced cancer had more deteriorated QOL than subjects with esophageal and gastric advanced cancer; however, the difference also was not statistically significant. Moreover, we presented that moderate malnutrition (GLIM stage 1) was correlated with better QOL than the severe stage (GLIM stage 2). Patients at risk of malnutrition (SGA A) had a better QOL in 4 domains compared to severely malnourished subjects (SGA C); however, the difference was statistically significant only in psychological domain. Similar results were obtained in Shahmoradi et al. study [20]. It was shown that PG-SGA scores significantly correlated with quality of life scores $(r 2=0.38, p<0.05)$, psychophysiological well-being $(r 2=0.37, p<0.05)$, functional well-being $(r 2=0.42, p<0.05)$, well-being $(r 2=0.07, p<0.05)[20]$. Indeed, it confirmed that malnutrition and more precisely the severity of malnutrition affect the patients' QOL.

\section{Conclusions}

To the best of our knowledge this is the first study comparing the QOL of patients with different stages of malnutrition according to new GLIM 2019 classification. In this study, we demonstrated that nutritional status and QOL is deteriorated in patients with head/neck, esophageal, and gastric cancer. According to the both tool, SGA and GLIM criteria 2019, most of them were severely malnourished. Additionally, the severity of malnutrition has an impact on QOL of cancer patients.

\section{Limitations}

The present study has some limitations. Firstly, the sample size is small. Secondly, the group is non-homogenous. No specified data concerning tumor stage and ongoing oncological therapy was reported.

\section{Abbreviations}

\section{ESPEN}

European Society for Clinical Nutrition and Metabolism

QOL

Quality of Life 
NRS 2002

Nutritional Risk Screening 2002

SGA

Subjective Global Assessment

\section{PG-SGA}

Patients-Generated Subjective Global Assessment

\section{GLIM}

Global Leadership Initiative on Malnutrition

\section{WHOQOL-Bref}

World Health Organization Quality of Life-Bref

\section{ONS}

oral nutritional supplement

PEG

percutaneous edoscopic gastrostomy

\section{BMI}

body mass index

NCJ

needle catheter jejunostomy

\section{Declarations}

\section{Ethics approval and consent to participate}

The study protocol has been approved by Independent Bioethics Committee for Scientific Research at Medical University of Gdańsk, Poland (the project indentification code: 422/2016). The patients declared agreement to participant in this study.

\section{Consent for publication}

Not applicable.

\section{Competing interests}

No conflict of interest.

\section{Funding}

No funding.

\section{Authors' contributions}

KKS - the major contributor in writing this manuscript, study design, and data collecting; KSŻ - study design and the major contributor in writing this manuscript; JR, MF, and MŚ - writing manuscript and languages corrections; WM - study design and mentor. 


\section{Acknowledgements}

No acknowledgments.

\section{Availability of data and materials}

The datasets used and analyzed in the current study are available from the corresponding author on reasonable request.

\section{References}

1. Arends J, Bachmann P, Baracos V, Barthelemy N, Bertz H, Bozzetti F, et al. ESPEN guidelines on nutrition in cancer patients. Clin Nutr. 2017;36(1):11-48.

2. Na B-G, Han S-S, Cho Y-A, Wie G-A, Kim J-Y, Lee J-M, et al. Nutritional Status of Patients with Cancer: A Prospective Cohort Study of 1,588 Hospitalized Patients. Nutr Cancer. 2018;70(8):1228-36.

3. Cordeiro L, de AF, Silva TH, Oliveira LC de, Nogueira Neto JF. Systemic Inflammation and Nutritional Status in Patients on Palliative Cancer Care: A Systematic Review of Observational Studies. Am J Hosp Palliat Care. 2019. doi:10.1177/1049909119886833.

4. Kaźmierczak-Siedlecka K, Folwarski M, Jankowska B, Spychalski P, Szafrański W, Baran M, Makarewicz W, Bryl E. Assessment of nutritional status of patients with cancer who are qualified for home enteral nutrition - a retrospective analysis. Eur $\mathrm{J}$ Transl Clin Med. 2020. doi:10.31373/ejtcm/120583.

5. Thoresen L, Fjeldstad I, Krogstad K, Kaasa S, Falkmer UG. Nutritional status of patients with advanced cancer: the value of using the subjective global assessment of nutritional status as a screening tool. Palliat Med. 2002;16(1):33-42.

6. Jeejeebhoy KN, Keller H, Gramlich L, Allard JP, Laporte M, Duerksen DR, i in. Nutritional assessment: comparison of clinical assessment and objective variables for the prediction of length of hospital stay and readmission. Am J Clin Nutr. 2015;101(5):956-65.

7. Allard JP, Keller H, Gramlich L, Jeejeebhoy KN, Laporte M, Duerksen DR. GLIM criteria has fair sensitivity and specificity for diagnosing malnutrition when using SGA as comparator. Clin Nutr. 2019. doi.org/10.1016/j.clnu.2019.12.004.

8. Ge T, Lin T, Yang J, Wang M. Nutritional status and related factors of patients with advanced lung cancer in northern China: a retrospective study. Cancer Manag Res. 2019;11:2225-31.

9. Cederholm T, Jensen GL, Correia MITD, Gonzalez MC, Fukushima R, Higashiguchi T, et al. GLIM criteria for the diagnosis of malnutrition - A consensus report from the global clinical nutrition community. Clin Nutr. 2019;38(1):1-9.

10. Rummans TA, Clark MM, Sloan JA, Frost MH, Bostwick JM, Atherton PJ, i in. Impacting Quality of Life for Patients With Advanced Cancer With a Structured Multidisciplinary Intervention: A Randomized Controlled Trial. J Clin Oncol. 2006;24(4):635-42.

11. Meneguin S, Matos TD, de S, Ferreira, de L da M, Meneguin SM, Matos S, TD de S, Ferreira M de. L da SM. Perception of cancer patients in palliative care about quality of life. Rev Bras Enferm. 2018;71(4):1998-2004.

12. Ahlam A, Hind M, Haddou Rahou B, Rachid R, Hassan E. Quality of life of Moroccan patients on the palliative phase of advanced cancer. BMC Res Notes. 2019;12(1):351.

13. Smith $\mathrm{E}$, Gomm S, Dickens $\mathrm{C}$. Assessing the independent contribution to quality of life from anxiety and depression in patients with advanced cancer. Palliat Med. 2003;17(6):509-13.

14. Jager-Wittenaar H, Ottery FD. Assessing nutritional status in cancer: role of the Patient-Generated Subjective Global Assessment. Curr Opin Clin Nutr Metab Care. 2017;20(5):322-9.

15. Contreras-Bolívar V, Sánchez-Torralvo FJ, Ruiz-Vico M, González-Almendros I, Barrios M, Padín S, et al. GLIM Criteria Using Hand Grip Strength Adequately Predict Six-Month Mortality in Cancer Inpatients. Nutrients. 2019;11(9):2043.

16. Wiegert EVM, Padilha P, de C, Peres. WAF. Performance of Patient-Generated Subjective Global Assessment (PG-SGA) in Patients With Advanced Cancer in Palliative Care. Nutr Clin Pract. 2017;32(5):675-81.

17. Souza Cunha M, Wiegert EVM, Calixto-Lima L, Oliveira LC. Relationship of nutritional status and inflammation with survival in patients with advanced cancer in palliative care. Nutr Burbank Los Angel Cty Calif. 2018;51-52:98-103.

18. Einarsson S, Laurell G, Tiblom Ehrsson Y. Mapping the frequency of malnutrition in patients with head and neck cancer using the GLIM Criteria for the Diagnosis of Malnutrition. Clin Nutr ESPEN. 2020. https://doi.org/10.1016/j.clnesp.2020.03.011. 
19. Bozzetti F. Quality of life and enteral nutrition. Curr Opin Clin Nutr Metab Care. 2008;11(5):661-5.

20. Shahmoradi N, Kandiah M, Peng LS. Impact of Nutritional Status on the Quality of Life of Advanced Cancer Patients in Hospice Home Care. Asian Pac J Cancer Prev. 2009;10(6):1003-09.

\section{Figures}

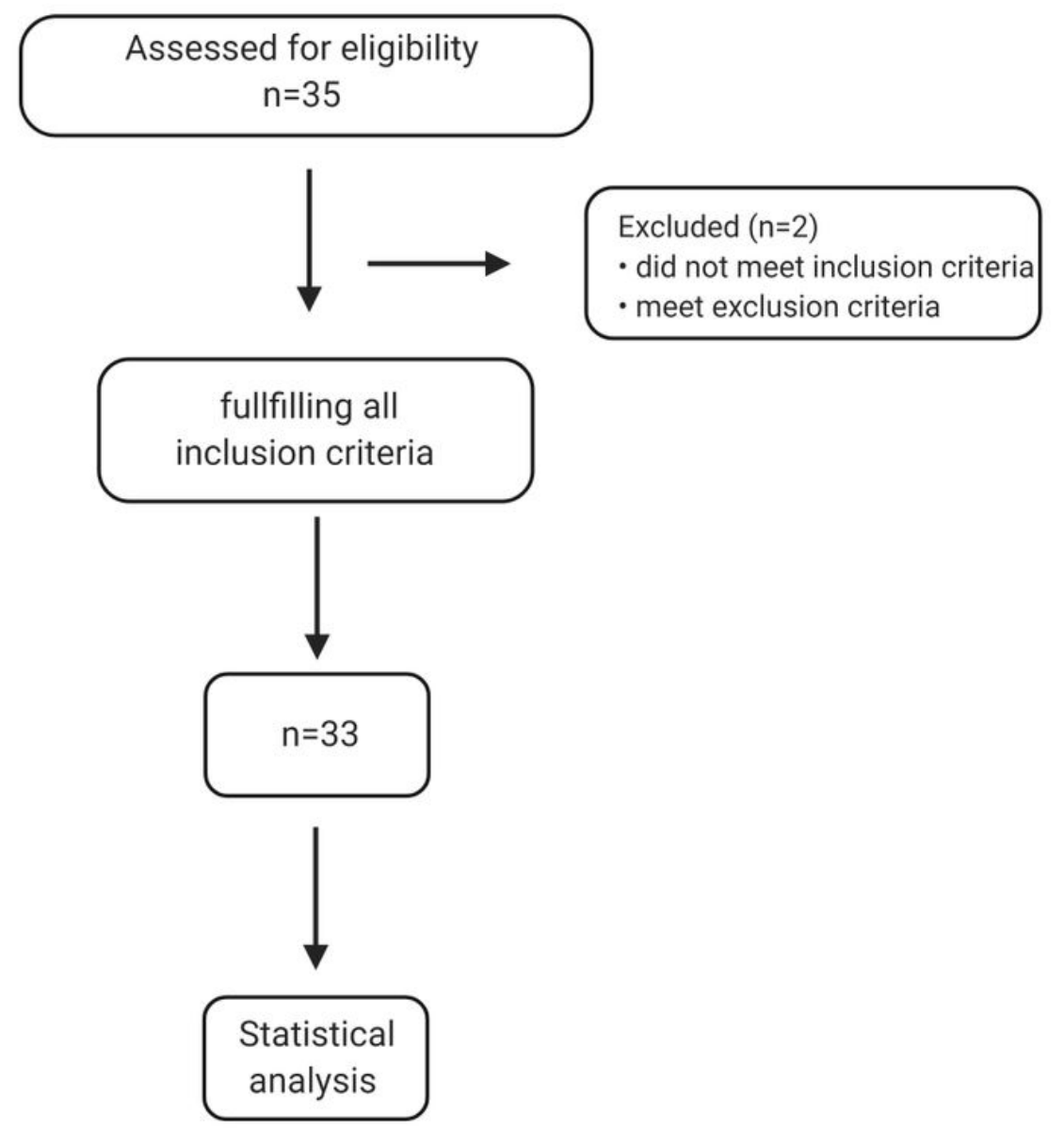

\section{Figure 1}

The flow-chart of this study. 